\title{
Differences in Intelligence and Creativity between Tattooed and Non-Tattooed Students
}

\author{
Anette Sandra Cebula ${ }^{1}$, Erich Kasten ${ }^{2}$ \\ ${ }^{1}$ Medical School Hamburg, University of Applied Sciences, Hamburg, Germany \\ ${ }^{2}$ Dept. of Neuropsychology, Medical School Hamburg, Hamburg, Germany \\ Email address: \\ sandra_cebula89@hotmail.com(A. S.Cebula),erikasten@aol.com (E. Kasten)
}

\section{To cite this article:}

Anette Sandra Cebula, Erich Kasten. Differences in Intelligence and Creativity between Tattooed and Non-Tattooed Students. Psychology and Behavioral Sciences. Vol. 4, No. 4, 2015, pp. 165-169. doi: 10.11648/j.pbs.20150404.14

\begin{abstract}
Background: In everyday life stereotypes, i.e. simplified imaginations about others are often built. One of innumerable stereotypes is that tattooed people drink too much alcohol, take always drugs, don't avoid risks and, maybe, they are even more stupid than the rest of humanity. On the other hand tattoos can be very artful. Therefore it is conceivable that tattooed people are more creative than others. Objective: This work is focusing on the question if there is a difference (a) in creativity and (b) in the crystallized intelligence between tattooed and non-tattooed persons. Methodology: To capture these characteristics an intelligence questionnaire (MWT-A) and five of eleven sub-tests of a creativity questionnaire (TDK) were used. To achieve a sufficient homogeneity between the samples, the survey was conducted only among students. A total of 104 persons were interviewed of which 50 people were tattooed and 54 non-tattooed, aged between 20 and 54 years. The survey took place at several universities and colleges in Hamburg and took about ten minutes per person. Results: There were no significant group differences regarding crystallized intelligence; moreover there was no correlation between having tattoos and creativity. Conclusion: Tattooed students seem to be neither less intelligent nor more creative than other students.
\end{abstract}

Keywords: Tattoo, Intelligence, Creativity, Body Modification

\section{Introduction}

The origin of tattoos is unexplainable, but there are several theses about the origins. Wohlrab, Stahl and Kappeler [25] assume that in the human history tattoos and piercings were symbols of beauty, independence and self-confidence. But nowadays tattoos also serve as an expression of protest and provocation towards society and parents.

The origins of Body-Modifications lay in countries where it was so hot that people were unable to underline their individuality with different clothing. About three hundred years ago, in South Africa, body paintings, scarifications, tattoos and piercings were used to give an expression of adulthood or to catch the attention of the opposite sex. Centuries later, sailors often had the names of their loved ones tattooed on their arms. In the Roman Empire they served as burned marks e.g. for slavery [17]. Tattoos were also used to mark the inmates, for example in German concentration camps during World War II [26].

Nowadays the body modifications serve as individual jewelry, which is worn to beautify the body, and as an expression for being able to live out the creativity on their own body. They also can have the function of a sign of membership in a group or a political opinion [16]. Furthermore tattoos can help to express a connection - for example, a couple that wears the same tattoo. For most people they serve as an expression of attractiveness and self-esteem [14, 25]. According to estimates of the "European United Tattoo Artists" (UETA), about eight million Germans are tattooed or pierced - with a strong upward trend. Among young people, it is one of four.

On the other hand, many people are not aware of the health risks of tattoos [4]. For instance, Kasten [16] or Worp et al. [26] described that particularly due to poor aftercare tattoos can cause inflammations; Goldstein noticed in 1967 allergic reactions caused by the tattoo ink [10]; also Long and Rickman [17] found infections after getting a tattoo. According to Catalano [5] particularly the head region can get damages due to the infection. Tattoo colors do not always stay where they were stung; a part of the color spreads into 
the whole body and can be detected mainly in the lymph nodes [8]. Worp et al. [26] found a high correlation between being tattooed and getting infected with hepatitis $\mathrm{B}$, hepatitis $\mathrm{C}$ and HIV if the tattoo was made under unsanitary conditions by a non-expert. Since 2009 there is a regulation about the inherent of tattoo-inks in Germany. Especially ink of older tattoos contains sometimes toxic compounds, which are capable of causing cancer [20]. Nowadays the aim is to make tattoos safer - firstly by the adherence to hygiene regulations with a profound education of people who work as tattoo-artists, and secondly by harmless colors.

In everyday life stereotypes, i.e. simplified imaginations about others are often built. One of innumerable stereotypes is that tattooed people drink too much alcohol, take always drugs, don't avoid any risks and, maybe, they are even more stupid than the rest of humanity. On the other hand tattoos can be very artful. Therefore it is conceivable that tattooed people are more creative than others.

On this basis, this article is focusing on the question if there is a difference (a) in creativity and (b) in the crystallized intelligence between tattooed and non-tattooed persons.

But what is intelligence? There are several theories about the IQ and how to measure it. This work is based on the two-factor model of intelligence of Cattell [6] who had distinguished between the liquid (fluid) and crystalline intelligence. Whereas the fluid intelligence is inherited and can't be influenced by the environment, the development of crystalline intelligence depends on the support thorough family, friends, school or education. Thurstone [23] had described in his primary factor model that intelligence is subdivided in seven categories (space, perceptual speed, numerical ability, memory, reasoning, word fluency and relations), which are equally important [2].

Creativity is the act to develop new imaginative ideas and of turn them into reality. Creativity is characterized by the ability to see things in a new way and make connections between seemingly unrelated phenomena Creativity is the ability to imagine new pictures and to find new solutions. A study of Getzels and Jackson [9] showed that different intelligence tests correlate with various creative tests. Based on his intelligence structure model Guilford [12] came to the conclusion that high intelligence is not equivalent with creativity but high creativity presupposes high intelligence. Sternberg [22] assumed in his triarchic intelligence theory that a person's intelligence is expressed by success in life. According to Sternberg, intelligence depends on the way how the individual processes information.

Guilford combined three aspects in his intelligence structure model [12]; namely the contents, the operations and the products. In his model Guilford referred directly to creativity. Consequently creativity describes on the one hand the abilities to see information from a different angle and to set things by variations in new relationships. On the other hand, creativity can be the versatile handling of information [12].

Guilford was not the only intelligence-researcher who included creativity in his model. Even Jäger [13] incorporated the ingenuity in his intelligence model. Thereby ingenuity is seen as equal with creativity. Guilford and Jäger were sure that intelligence includes creativity.

The idea that tattooed people are more creative than others is underlined by the fact that especially tattoo-artists, who are often heavy tattooed, must be creative. They were often asked to do extraordinary tattoos or to cover an old tattoo. In the book "Tattooing: Special Techniques" the tattooist Haramis Kalfar described that just the setting of light and shadow is a technique that requires at least imagination and spatial thinking. Kalfar declared that drawing fantasy figures or the detection of characteristic facial features requires mainly creativity [15]. In several tattoo forums a lot of tattoo artists explain that tattoos are not a protest against the society but a body art. The known Munich tattoo artist Aramis declares that tattoos are a sign of art [1].

On the other hand people with Body Modifications were attributed with very negative properties. In a study done by Dean in 2010, 31 percent of study participants without tattoos reported, that they consider people with tattoos as less intelligent, 42 percent said that they see tattooed people as less attractive, and 57 percent saw people with tattoos as a rebellious [7].

Meier [18] declared in his book "Inked: 0, $3 \mathrm{~mm}$ under the skin of the society, that tattoos are an indispensable part of the streetscape. Thus tattooed people are exposed by discrimination and stigmatization. To support this statement, Bammann [3] sees tattoos as deviant behavior. Feige [21] mentioned that this social attribution is generally connected with deprivation, insulting and inferiority. Because of these negative attributions, there can be developing an exclusion which can lead to lose the job.

In July 2012 a French study examined a correlation between wearing a tattoo and/or a piercing and the consumption of alcohol. A total of 2,970 college students (1,710 men and 1,260 women) were investigated. The authors came to the conclusion that those who had tattoos tended to alcohol excesses, while non-tattooed drank less alcohol [11].

Based on these discrepant facts the here presented study was performed to examine whether tattooed people really are more creative but also less intelligent. The first hypothesis is whether tattooed people are less intelligent than non-tattooed people. The second hypothesis is whether the tattooed are more creative than the non-tattooed.

\section{Methods}

For the quantitative collection of data two questionnaires were used. The first part of the questionnaire on the cover page contains a brief introduction and explanation of the confidentiality of data. Furthermore, socio-demographic data as gender, age, profession, the highest degree were collected on the cover sheet. In addition, the question was asked whether the participants are tattooed or not and, if this is the case, how big the tattoo is in square centimeters as well as the 
number of tattoos.

To measure the intelligence, the Multiple-Choice Vocabulary Intelligence Test (MWT-A) was used. The MWT-A measures only the crystallized intelligence (see above). The participants had to mark one word out of five which was correctly written. The 37 items of this test are arranged according to the degree of difficulty. The raw-data were transformed into a standard-IQ and a percent rank value. The average of the IQ scale is 100 . Values below 85 are conspicuously low; values above 115 are very good. An IQ below 85 indicates mental retardation.

For the investigation of creativity five subtests of the "Questionnaire for Divergent Thinking" (TDK) were used. Here, the number, quality, originality and newness of answers play an important role for the evaluation of the creativity of a participant. The values of this test can be represented as percentiles or T-values. The processing time was about 15 minutes for the whole test.

\section{Results}

\subsection{Sample}

In order to obtain a homogeneous sample, the requirement was to have finished secondary school and being a student at a university or college. The recruitment of the sample took place in Hamburg in various universities (Medical School Hamburg, University of Hamburg, Helmut Schmidt University and the High School of Applied Sciences Hamburg). In addition, an online survey was conducted. For this purpose, the participants received an online-link; here they could fill out the questionnaire online.

The basis for the empirical analysis provides a total sample of 106 subjects, 54 of whom had no tattoos on the body and 50 people had stung at least one tattoo. Two of the 106 subjects haven't had completed the questionnaire and their data were excluded. Due to the Multiple Choice Vocabulary Intelligence Test the minimum age for the study was 20 years. The age range of the subjects ranged from 20 to 54 years, with the average age of 25.5 year. Only two people were more than 50 years old. $59(56.7 \%)$ were female and $45(43.3 \%)$ were male. The following table shows the distribution of the gender and is based on whether they are tattooed or not tattooed.

Table 1. Distribution of gender based and tattoos.

\begin{tabular}{lllll}
\hline & $\mathbf{f ~ ( N )}$ & $\mathbf{m}(\mathbf{N})$ & $\mathbf{f}(\%)$ & $\mathbf{m}(\mathbf{\%})$ \\
\hline Tattooed & 29 & 21 & 27,9 & 20,2 \\
Non-tattooed & 30 & 24 & 28,8 & 23,1 \\
Total & 59 & 45 & 56,7 & 43,3 \\
\hline
\end{tabular}

Table 2. Comparison of values of tattooed and not tattooed.

\begin{tabular}{lllll}
\hline & N & Minimum & Maximum & $\begin{array}{l}\text { Average } \\
\pm \text { Standard } \\
\text { Deviation }\end{array}$ \\
\hline IQ no-Tattoo & 54 & 90,00 & 143,00 & $115,61 \pm 14,71$ \\
Creativity no-Tattoo & 54 & 4,00 & 46,00 & $17,57 \pm 10,91$ \\
IQ Tattoo & 50 & 80,00 & 143,00 & $113,16 \pm 13,91$ \\
Creativity Tattoo & 50 & 4,00 & 60,00 & $16,06 \pm 10,01$ \\
\hline
\end{tabular}

\subsection{Detailed Results}

Table 2 (see above) shows a general overview of the maximum and minimum values of the intelligence test and the creativity test. This table shows that the values of the tattooed group don't differ significantly from the non-tattooed group. While the tattooed participants have their highest value of 143 in the intelligence test and the highest value of 80 in the creativity test, the non-tattooed possess their highest value of 143 in the intelligence test and 90 in the creativity test. To calculate significant difference between these two groups, the Mann-Whitney-U-Test was performed.

First, the average values of both groups in the field of intelligence and creativity were compared. Figure 1 and Figure 2 show the results. The average value of non-tattooed in the creativity test is 17.57 and the standard deviation (SD) is 10.91. The average value of tattooed is 16.06 and the standard deviation is 10.01. The values of the tattooed and non-tattooed people are very close to each other and there is little difference in the field of creativity between tattooed and non-tattooed.

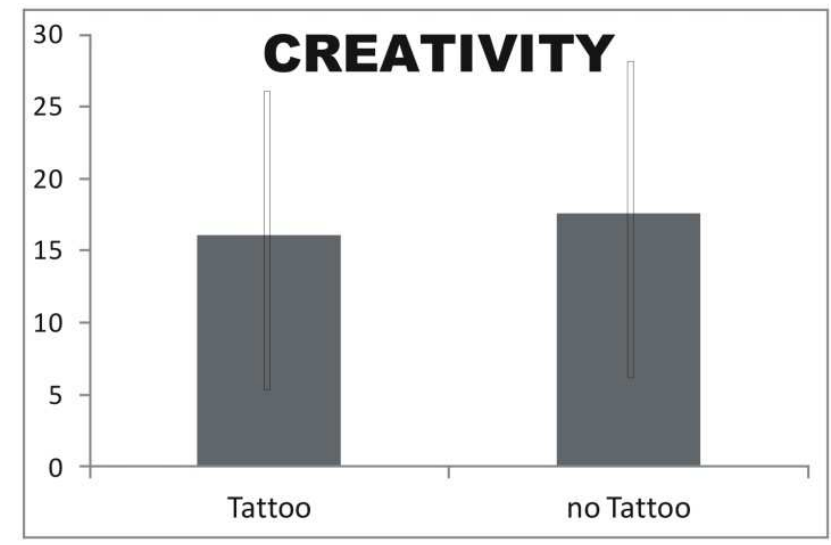

Figure 1. Results of the creativity test (average and standard deviation).

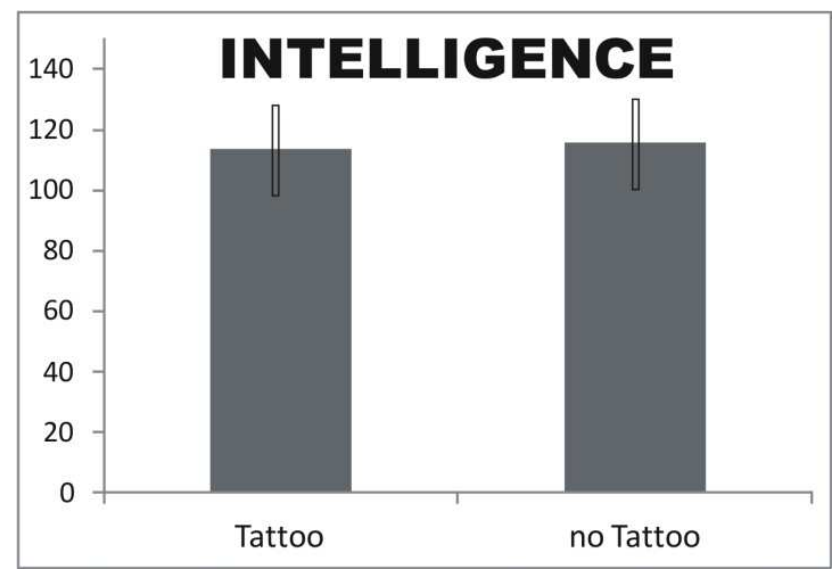

Figure 2. Results of the intelligence test (average and standard deviation).

The average value for non-tattooed in the area of the intelligence is located at IQ 115.61 with a standard deviation (SD) at 14.71. The average value of tattooed in the field of intelligence is IQ 113.6 and the standard deviation at 13.91. As for creativity, for intelligence is only little variation between the values of tattooed and non-tattooed participants. 
The first main hypothesis that has to be checked is whether tattooed people are less intelligent than non-tattooed people. The second main hypothesis is whether the tattooed are more creative than the non-tattooed. In this study the results of two independent samples were taken. For this reason, the Mann-Whitney U-test was performed. The U-test is a homogeneity test, which checks the significance of two independent distributions.

For the first main hypothesis the SPSS program calculated a value of $p=0.425$, which means the U-test $(U(50,54)=104$, $\mathrm{p}>0.05$ ) shows no significance between these two groups in the field of crystalline intelligence. Thus, the p-value is in the retention area. The null hypothesis, tattooed are as intelligent as non-tattooed, was maintained, and the alternative hypothesis, tattooed people are less intelligent than non-tattooed, was not accepted.

The U-test calculated in the field of creativity between the groups $(U(50.54)=104, p>0.05)$. That shows that there is no significance.

The second main hypothesis was tested on a $\alpha$-level of five percent (i.e. $\mathrm{p}<0.05$ ). The $\mathrm{p}$-value is 0.912 , so the $\mathrm{p}$-value is in the retention area. Here also the $\mathrm{p}$-value has to be cut in half so that one side can be tested. Thus, the p-value is 0.456 . Even with the one-sided test there is no significance. The null hypothesis is retained and the alternative hypothesis is rejected. Tattooed people therefore do not differ notably in terms of the creativity of non-tattooed people.

\section{Discussion}

The objective of this work was to find out whether there are differences in the crystalline intelligence and creativity between tattooed and non-tattooed people. The evaluation of intelligence and creativity of a questionnaire of 104 participating volunteers resulted in the conclusion that significant differences could not be detected - neither in the field of crystalline intelligence nor in the field of creativity.

The analysis of the main hypothesis took place on the basis of the data of the Mann-Whitney-U-test. The results show no significance in the field of intelligence between tattooed and non-tattooed people. The alternative hypothesis, tattooed people are less intelligent than non-tattooed, was not accepted. The null hypothesis, tattooed are intelligent as non-tattooed, is maintained. Furthermore, there are no differences in the field of creativity between tattooed and non-tattooed. Negative prejudices - against tattooed - are not justified with regard to their intelligence.

Although the general acceptance of tattoos is increasing in western society, having tattoos in certain social groups can be a heavy stigma. Tattoos were an important part of the culture of organized crime such as e.g. in the Russian Mafia and the Japanese Yakuza. In the west, tattoos are often associated with (former) prisoners (jail tattoos). So it is not surprising that in the workplace, especially in classical sectors such as trade, insurance and banks a striking body modification still is not tolerated. In spite of that tattoos and piercings are actually a private matter and should not be prohibited by the employer [22].

In order to achieve more significant results in the future, the following points should be included in this work. First, the crystalline intelligence comes from experiences that the human makes in his environment. It includes everyday experiences and memories of a person. In the process the human makes experiences, depending on the personality and preferences of an individual. One criticizing point at the edition of this questionnaire is that some socio demographic data were not collected. One of the most important aspects for acquiring general knowledge is social status. As an example, the parents' salary could be used. Another important aspect is the district where the volunteers live. According to a long-term study of the ISS AWO in 1997, which was continued in 2009 , poorer families have fewer resources than non- poor families. This is one of the reasons why the general education is often less pronounced in poorer neighborhoods [27]. Another important point for the detection of the crystalline intelligence is the genetic component. The intelligence is partly genetic and partly due to the environment. Numerous studies have shown that up to 75 percent intelligence is hereditary. One example is the twin study of Harden, Turkheimer \& Loehlin in 2007 with 839 pairs of twins. The study showed that both the environmental impact and the genetic components in interaction exerted an influence on the intelligence.

This small pilot study has several limitations. Choosing a short intelligence test is difficult. Many intelligence tests take a long time for processing. The MWT-A is a fairly quick test with a processing time of only five minutes. However, this measures only a part of the intelligence, namely the crystalline part. But intelligence is divided in many different areas and there is not a definitive consensus. Since only the crystallized intelligence is measured by the MWT-A, no conclusions to the other areas of intelligence (spatial, emotional, cognitive, etc.) can be provided. This criticism is not completely baseless. Intelligence is neither clearly defined nor easily measured. In contrast, other human dimensions (weight, height, muscle strength) can be measured objectively.

A disadvantage of the TDK is that long and interesting stories don't lead to more points.

An additional critique is that even objective psychological investigations can always capture only partial areas and often has nothing to do with success in life.

Due to the very small sample of 104 subjects of which 54 were not tattooed, no general statement can be made, regarding to the results. Also the nature of the cross sectional is a weakness of this study. Still this work does not distinguish between pictorial tattoos or lettering.

The state of research in the field of intelligence and creativity of tattooed and non-tattooed people suggests that this area still has too little attention. Many people draw conclusions about the intelligence of tattooed just because of prejudice and stigmatization. 


\section{Acknowledgements}

The authors thank all participants of this study.

\section{References}

[1] Arafat. (02. 05 2012). Focus. Abgerufen am 06. 062015 von http://www.focus.de/panorama/videos/tattoo-kuenstler-arafatmein-erstes-tattoo-stach-ich-mir-mit-acht-jahren_vid_31081.h tml

[2] Asendorpf (2007). Psychologie der Persönlichkeit. Springer.

[3] Bammann \& Stöver (2006). Tätowierungen im Strafvollzug. Oldenburg: BIS-Verlag der Carl von Ossietzky Universität Oldenburg.

[4] Boytchev (2013). Risiken von Tätowierungen. Berlin: Spiegel.

[5] Catalano (17.03 2000). When the body is the canvas, safety counts. Abgerufen am 08. 082014 von APB News: www.apbnews.com

[6] Cattell (1973). Personality and mood by questionnaire. Jossey-Bass Publishers.

[7] Dean (2010). Consumer perceptions of visible tattoos on service personnel. Managing Service Quality, p. 300-308.

[8] Dominguez, Alegre, García-Melgares, Laguna, Martín, Sanchéz, et al. (2008). Tattoo pigment in two lymph nodes in a patient with melanoma. Journal Compilation. European Acadamy of Dermatology and Venereology, p. 101-136.

[9] Getzels \& Jackson.(1962). Creativity and intelligence. New York: Wiley.

[10] Goldstein (1967). Mercery-Cadmium Sensitivity in Tattoos. Annals of Internal Medicine.

[11] Guéguen (12. Juli 2012). Tattoos, Piercings, and Alcohol Consumption. ISBRA, p. 1253-1256.

[12] Guilford (1967). The nature of human intelligence. University of Wisconsin- Madison: Mc Graw Hill series in psychology.

[13] Jäger, Süß, \& Beauducel (1997). Berliner IntelligenzstrukturTest (Bd. Form 4). (W. Sarges, \& H. Wottawa, Hrsg.) Lengerich: Pabst Science Publishers.
[14] Kächelen (2004). Tatau und Tattoo: Eine Epigraphik der Identitätskonstruktion. Aachen: Shaker .

[15] Kalfar (2012). Tätowieren: Spezielle Techniken. In H. Kalfar, \& H. Kalfar (Hrsg.), Tätowieren: Spezielle Techniken (Bd. 4.1. p. 3).

[16] Kasten (2006). Body Modification. München, Basel: Reinhardt Klimke, 2008

[17] Long \& Rickman. (1994). Infectious complications of tattoos. Clinical infectious diseases. Oxford Journals, p. 610-619.

[18] Meier (2010). Inked: 0,3 mm unter der Haut der Gesellschaft: Empirische Analyse gesellschaftlicher Diskriminierungs- und Exklusionsprozesse in der Moderne - untersucht am Phänomen der Tätowierung. Berlin: RabenStück Verlag.

[19] Mrasek (2013). Tätowierfarben- Gift im Arschgeweih. Berlin: Spiegel.

[20] Postel (2009). Fürs Leben gezeichnet. Frankfurter Allgemeine.

[21] Feige (2003). Ein Tattoo ist für immer: Die Geschichte der Tätowierung in Deutschland. Mit Fotografien aus einhundert Jahren Tattoo-Kuns, p. 412, Berlin: Schwarzkopf \& Schwarzkopf.

[22] Sternberg (1984). Toward a triarchic theory of human intelligence. Behavioral and Brain Sciences, 7, p. 269-287.

[23] Thurstone (1931). Multiple factor analysis, p. 406-427. Chicago: Psychological Review.

[24] Wessel \& Kasten (2014). Body-piercing and self-mulitation: A multifaceted relationship. American Journal of Applied Psychology. 3(4): p. 104-109

[25] Wohlrab, Stahl \& Kappeler (2007). Body Image. Modifying the body: Motivations for getting tattoed and pierced, 87-95. Göttingen: Science Direct.

[26] Worp, Boomstra, Coutinho, \& Hoek (01. 01 2006). Surveillance report. http://www. eurosurveillance. org/ ViewArticle.aspx?ArticleId=591

[27] Wüstendörfer. (04 2011). Familie und Armut. Familie und Armut-Eine Sonderauswertung des AWO-ISS-Datensatzes 1999 und 2003/04 über familiäre Bedingungen und ihre Auswirkungen auf Armut und Lebenslage der Kinder. Nürnberg, Frankfurt am Main: Institut für Sozialarbeit und Sozialpädagogik e.V. 